\title{
INFÂNCIAS E A LUTA DAS MULHERES: RESISTÊNCIA PLURAIS, FEMINISMOS E PEDAGOGIAS DESCOLONIZADORAS
}

\author{
CHILDHOOD AN WOMEN'S STRUGGLE: PLURAL RESISTANCES, FEMINISM AND \\ DECOLONIZING PEDAGOGIES
}

\author{
(Dhttps://orcid.org/0000-0002-1407-783XAdriana Alves da Silva ${ }^{\text {A }}$ \\ (iD https://orcid.org/0000-0001-9353-3110Vanderlete Pereira da Silva ${ }^{\text {B }}$ \\ ${ }^{\text {A } U n i v e r s i d a d e ~ d o ~ E s t a d o ~ d e ~ S a n t a ~ C a t a r i n a(U D E S C), ~ F l o r i a n o ́ p o l i s, S C, ~ B r a s i l ~}$ \\ ${ }^{\mathrm{B}}$ Universidade do Estado doAmazonas(UEA), Manaus,AM, Brasil \\ Recebido em: 13dez. 2021 | Aceito em:31 jan. 2022 \\ Correspondência:Adriana A. Silva(adriana.silva@udesc.br)
}

\begin{abstract}
Resumo
Este artigo traz interlocuções de pesquisas sobre infâncias, feminismos plurais e estudos decoloniais no âmbito do Gepedisc Culturas Infantis. Na primeira parte, apresenta um percurso de pesquisa e criação abordando a temática da cultura da violência, em uma perspectiva de análise interseccional, considerando o nó (Saffioti, 2015) que ata capitalismo-patriarcado, enredando classe, sexismo e racismo. Problematiza a cultura patriarcal (hooks, 2013) com suas pedagogias da crueldade (Segato, 2014) e aponta uma metodologia de pesquisa antropofágica na hipótese dos sinais remanescentes da cultura matriarcal (Andrade, 1990), através de poéticas e políticas da resistência em busca de pedagogias descolonizadoras. Nos interstícios do artigo, as vozes da poesia indígena ecoam com a poética de Márcia Wayna Kambeba, da etnia Omágua Kambeba.Na segunda parte, apresenta os resultados de uma pesquisa de doutorado acerca das formas de resistência das mulheres-mães que vivem com seus filhos e filhas na cidade de Manaus, capital do estado que concentra a maior população indígena do país. A pesquisa revela os efeitos da colonização na educação das crianças pequenininhas de 0 a 3 anos de idade, com foco nas questões de gênero e etnia, evidenciando a relação entre o processo de colonização e a forma como a colonialidade opera, criando entre os povos colonizados mecanismos de hierarquização que reforçam e reproduzem as desigualdades sociais, afetando o cuidado e a educação das crianças pequenininhas em ambientes urbanos.
\end{abstract}

Palavras-chave: Infâncias; Feminismos; Pedagogias descolonizadoras.

\section{Abstract}

This article brings dialogues from research on childhoods, plural feminisms and decolonial studies within the scope of Gepedisc Culturas Infantiles. In the first part, it presents a path of research and creation approaching the theme of the culture of violence, in an intersectional analysis perspective, considering the knot (Saffioti, 2015) that ties capitalism-patriarchy, entangling class, sexism and racism. It problematizes patriarchal culture (hooks, 2013) with its pedagogies of cruelty (Segato, 2014) and points to an anthropophagic research methodology in the hypothesis of the remaining signs of matriarchal culture (Andrade, 1990), through poetics and policies of resistance in search of decolonizing pedagogies. In the interstices of the article, the voices of indigenous poetry echo with the poetry of Márcia Wayna Kambeba, from the Omágua Kambeba ethnic group. In the second part, it presents the results of a doctoral research on the forms of resistance of women-mothers who live with their sons and daughters in the city 
of Manaus, capital of the state that concentrates the largest indigenous population in the country. The research reveals the effects of colonization on the education of little children from 0 to 3 years of age, focusing on gender and ethnicity issues, highlighting the relationship between the colonization process and the way coloniality operates, creating among the colonized peoples hierarchy mechanisms that reinforce and reproduce social inequalities, affecting the care and education of young children in urban environments.

Keywords:Childhoods; Feminisms; Deconolizing Pedagogies.

\section{Introdução}

Antes dos portugueses descobrirem o Brasil, o Brasil tinha descoberto a felicidade.

Oswald de Andrade, Manifesto Antropófago, 1928

A pandemia, que não causou as desigualdades, mas que evidenciou sua brutalidade, demonstra o quanto as crianças vivem em situação de vulnerabilidade. A violação de direitos, tanto com relação à garantia de condições básicas para sobrevivência, como alimentação, quanto as violências extremadas, que atingem um quantitativo expressivo de crianças em todo o país, sobretudo as crianças pequenininhas, colocam os adultos em xeque acerca dos rumos que estamos dando à continuidade da vida para os que sobreviverão.

Na continuidade da violência, que vai se reeditando na história do país desde o período da invasão portuguesa, o Brasil chega em 2022 ainda ocupando o quinto lugar no ranking mundial de feminicídio, segundo o Alto Comissariado das Nações Unidas pra os Direitos Humanos (ACNUDH). O país só perde para El Salvador, Colômbia, Guatemala e Rússia em número de casos de assassinato de mulheres. (ONU, 2020). Os dados revelam que a cada dia, em média, doze mulheres são assassinadas no país. Os alarmantes índices de feminicídio no Brasil refletem o desfecho trágico de um processo colonizador, que tem na cultura da violência a base estrutural das relações de poder, ou seja, uma violência patriarcal. Mata-se por 'amor', pela força que o homem tem no corpo e na vida das mulheres. Um direito secular de posse, construída historicamente pelas narrativas religiosas, legitimadas pelo Estado e sustentadas por projetos educacionais e suas pedagogias colonizadoras.

Fica a pergunta: uma vez que $90 \%$ da educação e do cuidado das crianças são realizados pelas mulheres, estas pedagogias fundamentalmente machistas estão sendo simplesmente reproduzidas? Segundo bell hooks, importante referência estadunidense do feminismo negro 
contemporâneo, em Pelo fim da violência (2018, p. 101), o combate à cultura da violência, compreendida como violência patriarcal, é responsabilidade de todos, homens e mulheres que não são só vítimas, mas também reprodutores da violência, que inevitavelmente resvala nas crianças.

Também destacamos que vivemos em um cenário de violência sistêmica que assola o Brasil e demais países da América Latina, com diferentes abordagens religiosas, que têm especial foco de perseguições para com as questões de gênero, como bem retrata o documentário Gênero sob ataque (2016). No Brasil, convivemos com uma disputa acirrada por rebanhos, com interesses econômicos e políticos, com a sua parcela de horror à brasileira junto das três bancadas: a evangélica-religiosa; a da bala, ligada aos militares, milicianos, e a do boi, com os ruralistas, compondo nosso trágico cenário político institucional.

A alteridade é no Brasil um dos sinais remanescentes da cultura matriarcal.

(Oswald de Andrade)

\section{Cultura da Violência: Patriarcado, Capitalismo e as Pedagogias da Crueldade}

Em Gênero Patriarcado e Violência, Saffioti (2015) apresenta relevante pesquisa a respeito da violência contra as mulheres no Brasil, realizada pela Fundação Perseu Abramo, no final dos anos de 1990. A obra traz análises dos enredamentos que envolvem as relações de gênero e a violência; segundo a autora, trata-se do entrelaçamento do racismo e do sexismo que sustentam a sociedade de classes, em um nó entre patriarcado-racismo-capitalismo (2015, p. 134), com uma estrutura de poder que unifica as três ordens de produção de desigualdades e perversidades sistêmicas de gênero, de raça/etnia e de classe social.

Falquet, em seu livro Pax neoliberalia: perspectivas feministas sobre (la reorganizacion de) la violência contra las mujeres (2017), também apresenta pesquisas no contexto latinoamericano (El Salvador, Guatemala e México), cruzando diferentes níveis de análises a respeito da violência contra as mulheres, em uma perspectiva global, com dinâmicas que imbricam sexo, raça e classe. Um sistema complexo, que também envolve as dinâmicas de resistência e o movimento transnacional de criação de estratégias coletivas em torno dos corpos-territórios das mulheres. 
Problematizar as mulheres a serviço do sistema genocida brasileiro, como a ministra Damares Alves, Sara Winter, a patroa da mãe do menino Miguel $^{i}$ na branquitude racista, sexista, elitista, compreendendo o quanto as categorias centrais dos feminismos críticos interseccionalidade e a consubstancialidade ajudam a entender que não existe a categoria uniforme de mulheres, crianças, famílias, pois os sujeitos são atravessados por suas relações de gênero, raça/etnia, classe e idade e por seus posicionamentos políticos.

Também ressaltamos na profissionalização e politização docente um fundamento ético de posicionalidade anticapitalista, antirracista, antipatriarcal. Revisitando o pensamento pioneiro da socióloga brasileira Heilieth Saffioti com o nó capitalista, na indissociabilidade do racismo, sexismo e na crítica radical ao patriarcado, visualizamos a possibilidade concreta em torno de uma Educação Infantil feminista, a partir do foco estratégico revolucionário de ação política na formação de professoras - profissionalização e politização docente.

É nessa perspectiva que propomos ressaltar em nossas formações a potência do movimento feminista, da maré feminista negra (FIGUEREIDO, 2020) com suas epistemologias insubmissas decoloniais, divulgando o pensamento feminismo marxista, que vem discutindo a divisão sexual do trabalho e a crise do trabalho reprodutivo na contemporaneidade, com a retomada política das greves nos Dias Internacionais das Mulheres - 8 de março (ARRUZA; BHATTACHARYA; FRASER, 2019). Tal movimento, reforça as pautas de combate à violência de gênero, a exploração e opressão das mulheres trabalhadoras, assim como problematiza criticamente a instituição família, como eixo do poder patriarcal nos desafios da educação e o cuidado das crianças pequenas, que historicamente têm sido responsabilidade das mulheres.

Na perspectiva de compreender as violências contra as mulheres no âmbito estrutural, encontramos, nas análises da antropóloga argentina Rita Segato (2013, 2014), importantes considerações dessa violência estrutural e as pedagogias da crueldade que tangenciam esse fenômeno de ordem global. Segundo Segato (2014), a violência estrutural tem nas guerras suas facetas mais explícitas, porém, assume formas híbridas e configurações múltiplas na atualidade. Nesta direção, destaca um novo cenário bélico mundial, que tem a guerra como meio e fim de exploração e dominação econômica.

E nesse "mercado" bélico, o corpo das mulheres se configura como um importante território de destruição, com excessos de crueldade e tortura sem precedentes na história das guerras. Segato (2014) ressalta que o contexto do neoliberalismo estrutura as novas perversas 
relações de poder, reconfigurando a territorialidade, a política, o estado, a economia e o próprio patriarcado, com novas configurações dos conflitos informais de guerras não convencionais que se expandem pelo mundo, mas especialmente explodem na América Latina, com o crime organizado, as guerras repressivas do estado e das milícias, a repressão policial, todo um aparado repressivo e truculento.

Rita Segato, que hoje assume umas das vozes mais importantes da luta feminista, salienta o quanto, apesar das conquistas legais, das vitórias no campo das políticas públicas, a vulnerabilidade perante a violência depredadora contra os corpos femininos ou feminizados tem aumentado. O marco do ponto de vista dos conflitos bélicos foram as guerras na Iugoslávia e em Ruanda, nas quais a violência sexual passou de danos colaterais, como historicamente sempre ocorria nas guerras, a assumir uma posição central como arma de guerra.

Nesta perspectiva, Segato salienta que a truculência vai se constituindo como fundamental nas relações de controle e manutenção dos corpos e territórios, tendo a pedagogia da crueldade como a estratégia de reprodução do sistema. Especialmente a crueldade em corpos frágeis - feminino ou feminizados- tem a função de demarcar e potencializar a dominação que é inerente e indissociável a todos os tipos de violência de gênero, porém, como afirma Rita Von Hundy (2019): “A mulher não é um centro de reabilitação"ii .

O corpo das mulheres é território simbólico de vitória nas disputas da ordem patriarcal nestas novas configurações de informalidade, em que a imposição do mais forte "se escreve" na subjugação do corpo feminino. Toda violência tem uma dimensão instrumental e outra expressiva; a violação sexual tem uma finalidade expressiva e coletiva, trata-se de uma outra finalidade em relação aos crimes de gênero, envolvendo violência doméstica e intimidade, porém, a estrutura patriarcal permanece com determinações de violências às mulheres associadas às facções, aos grupos rivais ou que se pretendem exterminar.

A defesa de Segato (2014) para crimes cometidos contra as mulheres em contextos de conflitos territoriais é que não são crimes de motivação sexual, mas sim de crimes de guerra, que devem ser analisados com novas lentes, visando incorporar novas categorias jurídicas do campo do Direito e especialmente dos Direitos Humanos e da justiça humanitária internacional.

Da mesma maneira, nas análises de como as crianças são usadas como recursos humanos, mão de obra barata, descartável na manutenção das atividades ilegais que desencadeiam os conflitos bélicos nos grandes centros urbanos. A ordem econômica-militar que atua nesse cenário informal e subterrâneo da segunda realidade depende de processos de 
desumanização deliberada e sistemática, com requintes de exibição de crueldade como garantias de controle territorial.

\section{Pedagogias Descolonizadoras: Poéticas e Políticas da Resistência}

A partir dos apontamentos apresentados que delineamos a urgência de um trabalho formativo crítico, problematizando as relações de gênero, considerando que são a grande maioria na Educação Básica, professoras, educadoras, com ou sem Magistério e/ou que tenham cursado Pedagogia, na perspectiva da profissionalização e politização da docência na Educação Infantil. E abordando as contradições estruturais da cisão entre educar e cuidar, como uma potência política de empoderamento perante as crises de reprodução social.

Dentre as muitas inquietações e possíveis questionamentos que este percurso nos incita, colocamos como foco alguns apontamentos referentes à nossa posicionalidade, como pesquisadoras/es, professoras/es, militantes, ativistas que atuam no campo da educação para/com as infâncias, perante os desafios da profissionalização e politização da docência, especialmente na Educação Infantil onde se concentra e se reproduz a dicotomia entre o educar e cuidar.

Nesta perspectiva, na indissociabilidade do educar e do cuidar, é que salientamos a base inicial de reflexão a respeito dos desafios da profissionalização e politização docente na Educação Infantil. Ao abordarmos a profissão docente voltada para Educação Infantil, ressaltamos que se trata de uma docência relativamente nova em sua especificidade, sendo inventada na e para a Educação Infantil, especialmente nos últimos 30 anos, tendo como marco a LDB 9394/1996, que institui a EI como primeira etapa da Educação Básica.

Cabe destacar a presente problematização, reforçada após a crise da pandemia da Covid19, tragédia global que evidenciou as contradições do trabalho doméstico e trouxe a centralidade da dimensão do Cuidado, categoria fundamental da existência humana, compreendida e situada no campo de estudos do Trabalho. Porém, destacamos que, na nossa cultura, a dinâmica do cuidado e da reprodução da vida, historicamente vem sendo construída por uma desigual divisão sexual do trabalho, em uma esfera privada, afetiva, na esfera do doméstico, essencialmente da ordem do feminino. Trabalho invisível, desvalorizado, pouco, mal ou não remunerado. 
A questão da predominância feminina da docência na Educação Infantil, no nosso modo de pensar, exige uma problematização e reflexão constante; nesta direção que a proposição de resgatar a história da luta por creche, do ponto de vista feminista (FARIA, 2005), juntamente ao sindicalismo de esquerda e dos movimentos sociais, é fundamental para um processo de profissionalização e politização docente.

A história da creche numa perspectiva feminista está situada em trajetórias de pesquisa, extensão e articulação política do GEPEDISC (Grupo de Estudos e Pesquisa em Educação e Diferenciação Sociocultural), linha Culturas Infantis, vinculado à Faculdade de Educação da Universidade Estadual de Campinas (SP), junto ao departamento de Ciências Sociais na Educação (DECISE), que, em 2021, celebrou seus 25 anos de luta pelo direito à infância e educação, local de onde falamos e nos posicionamos como pesquisadoras, inserida em um coletivo de pesquisa: criancista, criançóloga, marxista, feminista.

Destaca-se a práxis em torno da pesquisa militante a partir do Simpósio Temático Creche e Feminismo, no Seminário Internacional Fazendo Gênero, importante evento multidisciplinar na área de gênero e estudos feministas, envolvendo academia e movimentos sociais, realizado periodicamente na Universidade Federal de Santa Catarina.

A partir ou em conexão com a experiência desse evento, três publicações foram produzidas, publicadas no contexto coletivo do grupo de pesquisa e disponibilizadas gratuitamente; o primeiro, Creche e Feminismo: desafios atuais para uma educação descolonizadora (FINCO; GOBBI; FARIA, 2015), apresenta um olhar feminista para os direitos das crianças, da participação feminista na luta por creches, as questões de gênero na docência com as crianças, passando pelas mulheres operárias do ABC paulista, da cidadania dos bebês aos direitos das famílias trabalhadoras.

O segundo livro, Porque a creche é uma luta das mulheres: inquietações feministas já demonstram que as crianças pequenas são de responsabilidade de toda a sociedade! (TELES; SANTIAGO; FARIA, 2018), exalta o poder e a importância das redes feministas na universidade, com compromisso político na defesa dos diretos das mulheres e das crianças, dedicado à Marielle Franco "mulher, negra, mãe, feminista, socióloga, “cria da Maré", sua memória se expande e luto é verbo! Oferece um conjunto de artigos que abarca do feminismo negro ao feminismo marxista, da creche como bandeira da despatriarcalização, mas problematizando esse espaço em tempo de perda de direitos. E na necessidade de olharmos para 
as creches privadas, nas relações de classe e raça até as questões da descolonização do pensamento adultocêntico e da urgência de uma pedagogia da não violência.

Em "Isso aí é RACHISMO! Feminismo em estado de alerta na educação das crianças pequenas: transformações emancipatórias para pedagogias descolonizadoras (SILVA; FARIA; FINCO, 2019), na interlocução com pesquisadoras/es de diversas regiões do país, apresentamos pesquisas centradas nas crianças, suas resistências e transgressões, assim como as resistências das mulheres, abordando temas complexos como a transfobia de um feminismo radical. A questão da violência sexual contra as meninas e a negligência, impunidade em uma sociedade heteropatriarcal, passando pelas formas desiguais de engajamento das mulheres militantes, discutindo a pluralidade de feminismos, a emergência da categoria analítica da interseccionalidade e a divisão sexual do trabalho, a maternidade e as creches.

A partir dessas contribuições, e para a presente reflexão, destacamos duas delas: a primeira, A fertilidade me sufoca" maternidade, feminismo e creche: algumas interlocuções (SILVA, 2015) que, partindo de uma inspiração literária, tem o argumento central em torno das tensões na sexualidade das mulheres, envolvendo maternidade, direitos reprodutivos, divisão sexual do trabalho e a violência contra as mulheres. E em Creche: uma bandeira da despatriarcalização (SILVA; MACEDO, 2019), colocamos no centro do debate a estrutura patriarcal intrínseca ao sistema econômico capitalista que engendra as relações de classe, raça e gênero em um nó de opressão e exploração, sobretudo das mulheres. Ambos buscando contribuir nos desafios de compreendermos a maquinaria do patriarcado como um sistema complexo, movimento reflexivo fundamental para nos situarmos coletivamente, e combater a violência que é inerente a nossa organização social.

Nesta direção que ressaltamos a urgência nos processos de despatriarcalização das nossas instituições de educação e cuidado, envolvendo processos formativos que consideram um debate reflexivo em torno de três dimensões: trabalho e os desafios de profissionalização e politização docente. Problematizamos em nossos processos formativos, tanto na formação inicial como continuada quais os/as sujeitos/sujeitas das pesquisas, ensino e extensão, perguntando-se quem são as professoras que constroem a Educação Básica no Brasil? Mulheres das classes populares? Negras, indígenas, casadas, homoafetivas, heteronormatizadas, lésbicas?

Em nosso percurso, levantamos e defendemos a hipótese é que são múltiplas e complexas identidades, mas o que as une é que são professoras, ou seja, exercem como atividade profissional à docência. E as possíveis pedagogias descolonizadoras, suas poéticas e 
políticas da resistência incidem num processo histórico complexo de imbricações do trabalho das mulheres, alinhados ao trabalho doméstico, às questões de classe, raça/etnia e as expectativas de reprodução social ligadas à maternidade, nas "naturalizadas" atribuições das relações sociais de sexo, entre homens e mulheres.

\section{Amazônidas ${ }^{\mathrm{iii}}$}

Somos filhas da ribanceira

Netas de velhas benzedeiras,

Deusas da mata molhada,

Temos no urucum a pele encarnada,

Lavando roupa no rio, lavadeiras,

No corpo o gingado de carimbozeiras,

Temos a força da onça pintada,

Lutamos pela aldeia amada,

Mas, viver na cidade não tira o direito de ser,

Nação, ancestralidade, sabedoria, cultura,

Somos filhas de Nhanderú, Senerú, Nhandecy

O Brasil começou bem aqui...

Não nos sentimos aculturadas,

Temos a memória acesa,

E vivemos na certeza de que nossa aldeia

Resistirá sempre ao preconceito do invasor,

Somos a voz que ecoa. Resistência? Sim senhor!

\section{Lutas e Formas de Reexistências das Mães Manauaras para Educar e Cuidar dos Filhos e Filhas na Amazônia}

A singularidade e pluralidade étnica que compõem as infâncias brasileiras, sobretudo na cidade de Manaus, onde convivem crianças indígenas, caboclas, negras, migrantes e imigrantes, mais recentemente, vindos da Venezuela $^{\text {iv }}$, vivem o desafio de sobreviver à 
pandemia com imensas dificuldades para acessar os direitos básicos frente à exigência do distanciamento social, imposto pela medida sanitária para conter a propagação do vírus.

A separação do humano e do não humano e, com isso, o desprezo pelas vidas consideradas inferiores pelo capital, por isso subalternizadas, seguida da autorização para a destruição dos rios, das florestas, dos animais e de todas as formas de vida que se contrapõem à ideia de lucro, forjaram a barbárie que tomou conta da realidade vigente, sem resguardar nem mesmo as crianças e suas infâncias. Durante a pandemia, as hierarquizações de gênero e raça, que constituem e mantêm o capitalismo, com a racialização dos povos, a inferiorização das mulheres e o adultocentrismo, que menospreza os saberes e o potencial das crianças, ampliaram as desigualdades já existentes.

No bojo dos fortalecimentos e enfraquecimentos diários, na urgência da luta pela vida, vemo-nos diante de questões políticas que envolvem o miscigenado, que não se afirma como negro nem indígena (MUNANGA, 1999); os homens que, na mesma condição de explorados, se colocam como algozes das mulheres, aumentando a violência de gênero de forma deplorável (LUGONES, 2014), junto à desigual divisão sexual do trabalho que, em tempos pandêmicos, alargou-se consideravelmente ${ }^{\mathrm{v}}$. No meio dos enfrentamentos para assegurar a continuidade da vida, há as muitas crianças que não estão protegidas das violências que vivem os adultos. À margem dos direitos sociais constituídos, autorizados e legitimados pelo Estado, a ter suas infâncias e juventude interrompidas, como aconteceu com as $4.928^{\mathrm{vi}}$ crianças e jovens de até 19 anos, assassinadas de forma violenta no ano de 2019, vítimas da violência urbana, seguem as crianças e as/os jovens brasileiras/os rumo ao abismo.

Nessa perspectiva, a pesquisa de doutorado concluída em 2021, produzida no GEPEDISC - linha Culturas Infantis, investigou os elementos sociais, políticos e as pluralidades históricas da realidade amazônica, que pudessem ser tomados como representativos de concepções do educar e cuidar de crianças presentes nas alternativas criadas pelas mães manauaras. Desta forma, acessamos um campo teórico vasto, entrelaçado por relações que se aproximam e se distanciam, a fim de compreender a questão numa perspectiva mais ampla. No sentido de compreender a falta de creche pública em Manaus, encontramos um campo complexo, que só a interseccionalidade como ferramenta teórico-metodológica pôde nos fornecer o suporte necessário para refletir acerca das questões que nos interrogavam, e as que, com o aprofundamento da investigação, passaram a nos interrogar. Encontramos mais 
interrogações do que respostas nessa incursão. Dessa maneira, esperamos que estas sirvam como ponte para outras investigações; que sejam disseminadoras de outras tantas interrogações.

A complexidade da questão apontou alguns indicativos que nos levaram a refletir acerca da continuidade da condição de subalternidade em que as mulheres-mães e suas crianças estão imersas. Entendemos vivendo a pandemia e contando os mortos diariamente, que, quando nos falta o ar, se impõe diante de nós a busca pelo que nos falta, e nada mais! A precarização da vida dita as normas em que as elucubrações se tornam um luxo para poucos, quase que eliminando as condições para um tipo de pensar mais complexo. Compreendemos também que exigir à/ao outra/o que é asfixiado a pensar criticamente, sem se solidarizar com ela/e, também é uma forma de desumanidade.

O resultado da pesquisa, onde foram entrevistadas 12 mulheres, mães de crianças de 0 a 3 anos de idade, moradoras de um bairro com maior população na referida faixa etária (IBGE, 2010) e com apenas uma creche em funcionamento para atender a demanda, evidencia o poder da colonialidade, manifesto nas falas das mães enunciando o desejo em matricular o/a filho/a na creche para oferecer-lhes uma educação branca, europeia, distanciando-os/as da cultura indígena. A opção das mães manauaras pela escolarização desde a creche, pode ser traduzida como a construção de pontes para fazer as travessias que elas não tiveram oportunidade de fazer, mas que querem oferecer às/aos filhas/os. Diante do cenário de violência, a primeira opção das mães é pela vida da/o filha/o. O processo de libertação das opressões é posterior à decisão de se manter viva/o. A tomada de decisão pela vida precede a qualquer reflexão inerente à libertação das opressões. É nesse sentido que nossa afirmação de manter as/os filhas/os vivas/os é uma forma de resistência, para que outras lutas sejam possíveis.

As mulheres entrevistadas retratam a luta dessas mulheres e o desejo de proteger as filhas e os filhos a todo custo. Algumas vieram para a capital do estado atraída pelas promessas do progresso nas cidades, acreditando na escolarização dos filhos e filhas como ruptura das condições de opressão infligida pela pobreza. Para as mães, a escolarização pode ser a garantia de condições de vida diferentes, em que as dificuldades experimentadas na infância podem ser amenizadas.

Para compreender os modos de educar e cuidar das crianças pequenininhas pelas mães manauaras, é preciso pensar essa questão a partir do contexto da colonização, da exploração das Américas e, consequentemente, da formação da hegemonia capitalista. A colonialidade do poder, de gênero, do saber e do ser alteram, ressignificam, interferem e estão presentes também 
nos modos de educar e cuidar das crianças pelas mães, favorecendo a continuidade da subalternização dos povos, impondo uma forma de educação não para a libertação, mas para perpetuar as formas de opressão. No caso das mulheres-mães manauaras, com ascendência indígenas, distanciando-as dos valores culturais e da organização social dos povos originários.

Resultado da hegemonia cultural dos colonizadores, as diferentes identidades dos povos originários são tratadas como únicas, além do preconceito gerado entre as/os próprias/os miscigenadas/os, ascendentes das etnias indígenas que povoaram e povoam a região amazônica, e que rejeitam suas culturas de origem. A miscigenação, gerada pelo processo de colonização, criou/cria barreiras que fortalecem o preconceito, a exploração e a opressão, mesmo entre as camadas subalternizadas.

A colonialidade se expressa na internalização, depois de tantos séculos, do pensamento de inferioridade dos povos colonizados. O desprezo pelos saberes e pela cultura ancestral e valorização ao que é do outro, com prevalência ao pensamento categorial dicotômico: civilizado/bárbaro, humano/não humano, rico/pobre, superior/inferior. Como consequência, constatamos a opção das mães pelas creches, para que as/os filhas/os aprendam, desde muito cedo, os saberes do colonizador, combatido pelo pensamento antropofágico no grito pela libertação dado por Oswald de Andrade, no seu Manifesto Antropófago, ainda em 1928 vii, e que permanece ecoando em nossos ouvidos, e em outros tantos mais: "Queremos a Revolução Caraíba. Maior que a revolução Francesa. A unificação de todas as revoltas eficazes na direção do homem. Sem nós a Europa não teria sequer a sua pobre declaração dos direitos do homem" (ANDRADE, 1928).

As subjetividades produzidas pela colonialidade não deixam dúvidas da necessidade de apropriação do saber do colonizador e ocultamento do saber ancestral, que passa a se configurar como a marca do vencido. A rejeição aos saberes ancestrais, naturalizada pela ideologia neoliberal, se transforma falsamente na via de superação da condição subalterna. As mães aderem à ordem do capital, submetendo as/os filhas/os a modelos de educação que se contrapõem aos processos de luta pela libertação, porque querem tirar a/o filha/o da mira da bala "perdida", garantindo-lhes o direito de respirar, e acreditando ser esse o desvio da pobreza como destino.

Subjacente ao desejo das mães pela escolarização das crianças desde a creche, emergem as categorias gênero e raça, utilizadas pelo capitalismo para dominar, controlar e explorar os povos subalternizados, distanciando homens e mulheres, negras/os e indígenas, de modo a 
enfraquecer as lutas pela libertação. Construir perspectivas de lutas desviando da raiz propagadora dos problemas, que é o sistema capitalista e sem a inserção das categorias gênero e raça, é prosseguir perpetuando a condição de subalternizadas/os.

A força do capitalismo que emergiu da exploração e encobrimento da América Latina não se detém com a criação de legislações, embora estas sejam relevantes e legítimas, como foi a luta das mulheres por creches e a inclusão da creche como primeira etapa da Educação Básica nos marcos legais brasileiros. No entanto, o lastro de destruição que foi/vai sendo deixado pela lógica de acumulação capitalista e as pluralidades históricas que marcam a formação do povo brasileiro, especialmente em relação à Região Amazônica, com forte presença dos povos originários, não favorece a distribuição igualitária dos benefícios das legislações. Há sempre inclusões de poucos e exclusões de muitos, causando enormes desigualdades. A negligência do Estado com relação ao direito à educação para as crianças de 0 a 3 anos de idade em creches públicas no contexto manauara é um exemplo disso.

Não houve, e permanece não havendo, a garantia do direito às diferenças culturais decorrentes do pluralismo histórico, com ampla repercussão nos modos de organização social dos povos e suas ancestralidades, o que implica a permanência do não reconhecimento do outro na sua diferença, de forma digna e legítima. Talvez precisemos discutir a educação das crianças pequenininhas nesse sentido, isto é, não se submetendo às categorias da Base Nacional Comum Curricular, as quais vão na contramão do pluralismo histórico, que está no centro da questão aqui apresentada.

As mães manauaras não têm opção na educação das suas crianças, diante da destruição do modelo comunitário de organização, causada pelo sistema moderno/colonial de gênero. A opressão que vitima os homens, fomentada pelo patriarcado, sobretudo no uso do mandato de masculinidade, construído e perpetuado por uma pedagogia da violência, como expôs Segato (2005, 2018), coloca sobre eles o fardo que em última instância os empurra para a morte.

Em outras palavras, essa opressão divide e fragiliza a luta contra os diferentes modos de exercer o poder patriarcal, porque dicotomiza e acirra as disputas que mantêm hierarquizações ente homens e mulheres. Sem a participação dos pais das crianças, desamparadas pelas garantias legais e vítimas das políticas públicas excludentes do Estado brasileiro, as mães optam pelo que lhes parece a chance das/os filhas/os, subverterem a lógica da desigualdade do poder estatal que, ao negligenciar o direito das mulheres, das crianças e das famílias, em suas diversas 
configurações, atua, sobretudo, contra as populações empobrecidas, historicamente excluídas e invisibilizadas.

A base social comunitária de produção e distribuição, que impede a divisão social do trabalho entre ricos e pobres, além de tornar possível o exercício das lideranças por pessoas mais velhas, foi experimentada por essas mulheres-mães há bem pouco tempo, por meio da prática dos ajuris $^{\text {viii }}$, deflagrados pelas cheias e vazantes do rio. Como descrevem os Xavante em seus desabafos, registrados no curta Damã Rowaihu'udzé - Pra todo mundo ficar sabendo (2000): “antes desta terra chamar Brasil, nossos avós já estavam aqui há muito tempo. Nossos avós aprendiam a ser Xavante, caçando e pescando na beira do rio". A escola fora da aldeia significou para os Xavante, assim como para os povos originários que vivem na Amazônia, a destruição de seus saberes e suas crenças. Tudo isso foi e continua sendo destruído pelo capitalismo, pela incompatibilidade com sua lógica e seu modo de produção e circulação de mercadorias.

Da mesma forma, a divisão, a fragmentação e a hierarquização são armas potentes usadas pelo capitalismo para destruir os laços comunitários, e se manter no controle e exploração dos povos subalternizados. Manter a divisão, fragmentação e hierarquização estruturadas na raiz patriarcal seria um grande equívoco diante da revolução que precisa ser feita.

Conhecer as formas das mães manauaras de educar e cuidar das crianças confirma a ideia de que qualquer mudança na estrutura da sociedade, se faz pela luta de classes, que deve ser pensada em articulação com as lutas antirracistas e feministas. A luta pela libertação se fará a partir da união dos movimentos sociais contra a opressão sexista e racial. Ou fazemos a luta conjuntamente contra as opressões patriarcais ou não há avanços, frente ao legado de desigualdades e injustiças sociais forjado pela colonialidade. Nesse sentido, a pandemia apenas contribuiu para aprofundar o que já era aviltante.

O desamparo das mulheres-mães para educar e cuidar das/os filhas/os e a indefinição dos rumos que podem tomar na vida criam o ambiente de angústia e terror, necessário para a manutenção da subalternidade e o impedimento das lutas por libertação. A angústia das mulheres, especialmente das mães manauaras, pode ser compreendida, na perspectiva decolonial $^{\text {ix }}$, como uma das manifestações de como o poder colonial perpetua ao longo da história suas formas específicas de opressão e subalternidade. 
Embora o cenário seja desolador com as tantas tragédias e ameaças às diversas formas de vida que habitam o planeta, as contradições tornam possível o avanço das forças que se opõem aos imperativos da globalização. Nesse sentido, as mulheres têm sido grandes protagonistas, como destaca a filósofa italiana Sílvia Federici (2020). Responsáveis pelos cuidados na reprodução das famílias, as mulheres estão no centro dos problemas estruturais da sociedade e são afetadas diretamente pela destruição causada pelo capitalismo, que vão desde a avassaladora degradação ambiental, com a derrubada da floresta e o aumento dos garimpos na Amazônia, até os macros problemas urbanos, agravados pela pandemia. Desta forma, a retirada de direitos e os processos de exclusão têm provocado outras maneiras de pensar, formas alternativas de luta pela vida, fortalecendo ações coletivas de resistência, nas quais as mulheres se destacam pelo fato de que são capazes de inventar diferentes modos de tecer outras tramas comunitárias, que têm garantido a sobrevivência de suas filhas e de seus filhos.

Quanto à maternidade indígena, não houve uma aproximação mais direta, a fim de entender os modos de cuidar e educar das crianças pequenininhas de mulheres de etnias diferentes que vivem em Manaus. Fica como sugestão para as próximas pesquisas, pois acreditamos que possa ampliar sobremaneira a compreensão acerca das lutas das mulheres contra o exercício do poder colonial de seus corpos e suas formas de vida. Novos estudos nessa direção podem contribuir de modo determinante com as políticas públicas voltadas para o educar e cuidar das crianças na região amazônica.

O exercício antropofágico no decurso da produção desta pesquisa nos retirou/retira e nos libertou/liberta continuamente das amarras que nos prenderam/prendem à condição de mulheres subalternizadas, imposta de diversos modos ao longo da nossa existência. Com isso, reiteramos nossa atuação e compromisso na luta por uma educação pública libertadora, começando desde a creche, para todas/os que vivem na Amazônia.

As reconfigurações do sistema político e econômico estão em curso de forma mais acelerada com a pandemia. As mudanças ideológicas daí decorrentes, certamente, recairão em novas formas de tratar a população empobrecida pelo capitalismo, com discursos e práticas eugenistas significando mais segregação e exclusão. Nesta perspectiva, aproximar a universidade das camadas populares passa a ser uma das tarefas mais urgentes de nosso tempo.

A pandemia tem estreitado o contato da população com os resultados do trabalho da ciência. As pesquisas científicas para a descoberta e produção das vacinas, bem como a busca de remédios para a cura da Covid-19, têm colocado em evidência a necessidade e valorização 
do trabalho das/dos pesquisadoras/es. A crise atual que vivemos pode ser entendida, conforme Hanna Arendt (2013), em sua positividade, isto é, como o momento oportuno para pensar o mundo de outras maneiras, abrindo novas possibilidades de conhecer o trabalho das/os pesquisadoras/es e as formas de produzir conhecimento científico no país.

\section{Educação Indígena ${ }^{x}$}

Ainda pequeno na aldeia

Na vivência com os irmãos,

Plantar macaxeira, tirar lenha,

Comer peixe com pirão,

É ensino, é educação.

Ir pra beira tomar banho,

Pegar cará e mandí,

Ver o sol se esconder

E esperar a lua se vestir,

Se vem cheia é alegria

Coisa boa vem por aí,

E com sua luz toda aldeia,

Vai cantar, dançar, se divertir.

Aprender a colher o tento na mata,

Fazer cocar de miriti,

A juntar as penas que vem das aves,

Seguindo as orientações de Waimí.

É da floresta que vem

A palha que a Uka vai cobrir,

Tecer nelas nossas memórias

Na folha de urucarí.

$\mathrm{Na}$ aldeia é assim a educação

Que desde séculos aprendi,

Conviver com a natureza 
Sem agredir, nem exaurir,

Se hoje no século XXI

Tens a mata e a biodiversidade,

Nesse verde eu cresci

E conheci sua bondade,

Partilhar água e sombra,

Sem ver nisso tanta maldade.

Mas logo veio o "outro",

E mostrou-me com sua maldade,

A importância da escrita

E vi nela uma necessidade,

Fui estudar na escola do branco

Para entender sua realidade.

Compreendi que a cultura é um rio

Corre manso para os braços do mar,

Assim não existem fronteiras

Para aprender, lutar e caminhar.

Hoje estamos nas Universidades,

Levamos junto nosso lugar,

A construção do conhecimento é uma teia,

Que liga a tua cidade com minha aldeia.

Sendo que minha identidade se constrói

Nas peculiaridades que em mim permeia,

Minha casa na cidade é também a minha aldeia,

Não perdemos nossa essência,

Somos o fino grão de areia!

\section{Considerações Finais}

Após a explanação deste intenso percurso reflexivo, que embora tenha focado em duas pesquisas, uma tese de doutoramento e uma que surgiu de outra tese, ambas em continuidades e na interlocução com um processo de 25 anos de estudos, militâncias e afinações das nossas 
lentes em busca de PEDAGOGIAS DESCOLONIZADORAS, na perspectiva da pesquisa, da criação e da afirmação de uma identidade e especificidade, da pedagogia da escuta, das diferenças, na altura das crianças, na relação com a natureza e a cultura como fundamentos centrais, alinhando metodologias de pesquisa e criação antropofágicas e compromisso de atuar frente aos desafios da politização docente.

$\mathrm{Na}$ tessitura da pesquisa, criação e atuação política alinhamo-nos contra as pedagogias da crueldade, partindo de um pressuposto feminista em que a creche é compreendida como lócus privilegiado na construção de práticas de educação e cuidado descolonizadoras, embasadas em pedagogias emancipatórias.

A creche como espaço e tempo de direitos tem a criança pequena em sua centralidade, as mulheres em sua maioria docentes (com diploma e sem diploma), protagonistas ativas no combate a múltiplas formas de opressão, violência e discriminação, evidenciando esse território na/da pequena infância como fundamental na vida contemporânea de muitas mulheres, permeado de contradições e possibilidades.

Inspiramo-nos em projetos do passado, como os parques infantis criados, dentre outros, por Mario de Andrade, em 1935, que são a origem da rede de Educação Infantil paulistana (FARIA, 1999):

\begin{abstract}
Os parques infantis criados por Mário de Andrade em 1935 podem ser considerados como a origem da rede de educação infantil paulistana (FARIA,1995) - a primeira experiência brasileira pública municipal de educação (embora não-escolar) para crianças de famílias operárias que tiveram a oportunidade de brincar, de ser educadas e cuidadas, de conviver com a natureza, de movimentarem-se em grandes espaços e não em salas de aula. Lá produziam cultura e conviviam com a diversidade da cultura nacional, quando o cuidado e a educação não estavam antagonizados, e a educação, a assistência e a cultura estavam macunaimicamente integradas, no tríplice objetivo parqueano: educar, assistir e recrear (FARIA, 1999, p. 61-62).
\end{abstract}

Em todo o Brasil encontramos redes municipais de Educação Infantil resistindo às políticas públicas neoliberais de privatização da educação. Florianópolis é uma das referências nacionais, pela qualidade e inovação, especialmente na pesquisa com bebês (COUTINHO; SCHMITT, 2021) com docentes pesquisadoras e unidades educativas que respeitam os direitos das crianças pequenas, envolvem as famílias, formam continuamente suas profissionais docentes, articulando pesquisas acadêmicas, práticas pedagógicas e políticas nacionais democráticas. 
Nesta perspectiva, temos construído proposições concretas de formação continuada, alinhando pesquisas acadêmicas aos movimentos sociais, inspirando-se na metodologia do Fazendo Gênero/IEG - importante evento que ocorre periodicamente na Universidade Federal de Santa Catarina (UFSC), de produção crítico reflexiva, resistência política formativa e no princípio era a ação, tendo nas lutas das mulheres um potente princípio educativo para a profissionalização e politização docente na Educação Infantil e nos anos iniciais da Educação Básica.

Compreendemos que uma educação emancipadora prevê professoras/es e educadoras/es com o pensamento descolonizado, questionando todas as formas de autoritarismo e abolindo as formas de violência, atentas e "denunciando aspectos da educação sexista" e colonizadora, "evidenciando as estratégias de resistência que contribuem para a construção de uma educação mais igualitária no convívio das diferenças de idade, gênero, classe e raça.” (FINCO; GOBBI; FARIA, 2015)

É nessa direção que buscamos uma pedagogia da infância interseccional com perspectiva feminista (SILVA, 2020), que tenha em sua múltipla intencionalidade pedagógica a promoção de ações educativas por meio de intervenções artísticas - em diversas linguagens, mas especialmente as que problematizem as narrativas tradicionais dos contos de fadas (SILVA, 2018). Narrativas que se configuram como clássicos infantis mundiais e podem ser conectados com uma perspectiva de feminismo transnacional (SILVA; FARIA; FINCO, 2019), como chave à problematização das violências que perpassam as relações de gênero, buscando desconstruir estereótipos e normatizações de comportamentos entre homens/meninos e mulheres/meninas.

Questionamos nos processos formativos como vamos abolir todas as formas de violência se elas começam na reprodução de histórias machistas e em práticas violentas no espaço doméstico, em casa, com a tal "palmadinha que não dói”, dada pela mãe e pelo pai? Como educar crianças feministas (ADICHIE, 2017) com as formas colonizadoras do adultocentrismo?

Astrid Lindgren (1907-2002), autora da personagem sueca transgressora Pippi Meia Longa, quando recebeu em 1978 o Prêmio da Paz dos editores alemães, apresentou o discurso Violência jamais, alertando as crianças para não obedecerem aos adultos sem que eles justificassem por que deveriam ser obedecidos. Como era a primeira vez que o prêmio era dado 
a uma autora de Literatura Infantil, ela perguntava: "Será que tem um defeito de fabricação na espécie humana já que recorremos sempre à violência?” (LINDGREN, 1978)

Por fim, sem finalizar, pois os percursos seguem e a formação é continuada, ainda nesta perspectiva crítica, não podemos nos abster de nos posicionarmos perante a tragédia de uma crise sanitária estrutural, pandêmica, potencializada no contexto brasileiro, com mais de 600 mil mortos, a partir das marcas históricas do horror de mais de 500 anos de colonização, com uma série de genocídios, estupros, feminicídios, infanticídios, dentre outras violações de direitos humanos. Ressaltamos a urgência de metodologias de pesquisa, ensino e extensão em torno de práxis transformadora na Educação das Infâncias brasileiras que tem como concepção que o direito à vida, a alegria e a liberdade é uma luta constante, inspirada em Angela Davis (2016), em que as condições impõem resistir para existir.

\section{Referências}

ADICHIE, Chimamanda N. Para educar crianças feministas: um manifesto. São Paulo: Cia das Letras, 2017.

ANDRADE, OSWALD. Manifesto Antropófago e Manifesto da poesia pau-brasil. In A utopia Antropofágica. São Paulo: Globo: Secretaria do Estado da Cultura, 1990.

ARENDT, Hannah. Entre o Passado e o Futuro. Trad. Mauro Barbosa. 7. ed. São Paulo: Editora Perspectiva, 2013.

ARRUZA, Cinzia; BHATTACHARYA, Tithi; FRASER, Nancy. Feminismo para os 99\%: um manifesto. São Paulo: Boitempo, 2019.

COUTINHO, Angela M. Scalabrin; SCHMITT, Rosinete Valdeci. A pesquisa com/sobre bebês no Nupein: análise da trajetória. DossiêPerspectivas de pesquisa na educação infantil: 30 anos de trajetóriaRevista Zero-a-Seis, Florianópolis, v. 23, n. 44,p. 1474-1499 , jul/dez. 2021.

DAMÃ Rowaihu'udzé - Pra todo mundo ficar sabendo. Direção: BIASE, Helena de; PUZZO, Gianni; RURI'Õ, Lucas; TOPITIRO, Hiparidi. Anthares Multimídia Vídeo Produções. 2000. 1 vídeo (16 min). Publicado pelo canal Anthares Multimídia. Disponível em: https://www.youtube.com/watch?v=K35s3VkE30Y Acesso em: 12 mar. 2021.

DAVIS, Angela. Mulheres, raça e classe. São Paulo: Boitempo, 2016.

FARIA, Ana Lúcia. G. de. A contribuição dos parques infantis de Mário de Andrade para a construção de uma pedagogia da educação infantil. Educ. Soc, Campinas, v. 20, n. 69, p. 6091, dez. 1999. 
As origens da rede pública municipal de educação infantil na cidade de São Paulo.

Proposições, Campinas,v. 6, n.17,p.34-45, dez.1995. (17), p. 34-45, 1995.

FEDERICI, Silvia. Mulheres e caça às bruxas: da Idade Média aos dias atuais. São Paulo: Boitempo, 2019.

Na luta para mudar o mundo: mulheres, reprodução e resistência na América Latina. Tradução de Luciana Benetti Marques Valio. Revista Estudos Feministas, Florianópolis, v. 28, n. 2, e70010, 2020.

FINCO, Daniela; GOBBI, Marcia A.; FARIA, Ana Lúcia Goulart de. Creche e Feminismo: desafios atuais para uma educação descolonizadora. Campinas, SP: Edições Leitura Crítica; Associação de Leitura do Brasil - ALB; São Paulo: Fundação Carlos Chagas - FCC, 2015.

GALEANO, Eduardo. Mulheres. Porto Alegre: L\&PM, 2019.

HOOKS, bell. O feminismo é para todo mundo: políticas arrebatadoras. Rio de Janeiro: Rosa dos Tempos, 2018.

LINDGREN, Astrid. Mai violenza! Suécia: Salingon Förlag, Lidingö,1978.

LUGONES, Maria. Rumo a um feminismo descolonial. Revista Estudos Feministas, Florianópolis, v. 22, n. 3, p. 935-952, set. 2014.

MIGNOLO, Walter D. História locais/Projetos globais: colonialidade, saberes subalternos e pensamento limiar. Tradução de Solange Ribeiro de Oliveira. Belo Horizonte: Ed. UFMG, 2003.

MIGNOLO, W. D. Colonialidade: o lado mais escuro da modernidade. Revista Brasileira de Ciências Sociais. São Paulo, v. 32, n. 94, 2017. Disponível em: www.scielo.br/pdf/rbcsoc/v32n94/0102-6909-rbcsoc-3294022017.pdf . Acesso em: 3 maio 2019.

MUNANGA, Kabengele. Rediscutindo a mestiçagem no Brasil. Vozes, 1999.

QUIJANO, Aníbal. Colonialidade do poder, eurocentrismo e América Latina. In: LANDER, Edgardo (org). A colonialidade do saber: eurocentrismo e ciências sociais. Perspectivas latinoamericanas. Buenos Aires: CLACSO, setembro 2005, p. 107 - 130.

QUIJANO, Aníbal. Colonialidade, poder, globalização e democracia. Novos rumos, n. 37, p. 4-28, 2002.

SAFFIOTI, Heleieth. Gênero patriarcado violência. São Paulo: Expressão Popular, 2015.

SANTIAGO, Flavio; FARIA, Ana. Lúcia Goulart de. Da descolonização do pensamento adultocêntrico à educação não sexista desde a creche: por uma pedagogia da não violência. In: 
TELES, M. A. A.; SANTIAGO, F.; FARIA, A. L. G. de. (orgs.) Por que a creche é uma luta das mulheres? Inquietações feministas já demonstram que as crianças pequenas são de responsabilidade de toda a sociedade! São Carlos: Pedro \& João Editores, 2018. p. 250-277.

SEGATO, Rita. L. Las nuevas formas de la guerra y el cuerpo de las mujeres. Revista Sociedade e Estado, v. 29, n. 2, p. 341-371, Brasilia, maio/ago. 2014.

Libros, 2018.

. Contra-pedagogías de la crueldad. Ciudad Autónoma de Buenos Aires: Prometeo

SILVA, Adriana.A. Niunamenos: feminismo, pedagogias e poéticas da resistência. In:

FINCO, Daniela; SILVA, Adriana A.; FARIA, Ana Lúcia de Goulart. (orgs.) Dossiê Feminismo em estado de alerta na educação de crianças pequenas em creches e pré-escolas.

Revista Zero-a-Seis,Florianópolis, v. 20, p. 221-234, jan./jul. 2018.

SILVA, Adriana A.; MACEDO, Elina. Creche: uma bandeira da despatriarcalização. In:

TELES, Maria Amélia A.; SANTIAGO, Flávio; FARIA, Ana Lúcia Goulart de. (Orgs.) Por que a creche é uma luta das mulheres? Inquietações feministas já demonstram que as crianças pequenas são de responsabilidade de toda a sociedade! São Carlos: Pedro \& João Editores, 2018. p.145-162.

SILVA, Adriana. A. Por uma educação infantil feminista: pedagogia, política e poéticas da resistência. In:BARREIRO, A.; CAVALCANTE, N. A. da S.; FARIA, A. L. G. de (orgs.) Pesquisas e pedagogias: educação para as diferenças. Uberlândia: Navegando Publicações, 2020. p. 203-219.

SILVA, Vanderlete Pereira da. Mães Manauaras e a educação das crianças pequenininhas: pluralidades históricas e resistência na cidade da floresta. Tese de Doutorado. Faculdade de Educação. Unicamp. Campinas, 2021.

TELES, Maria Amélia de A. Breve história do feminismo no Brasil e outros ensaios. São Paulo: Editora Alameda, 2017.

\section{Filmografia}

QUEM MATOU ELOÁ. Direção: Lívia Perez. Produção: Doctela, Brasil: , 2015.

GÊNERO SOB ATAQUE. Direção: Jerónimo Centurión. Produção: Clacai (Consórcio Latino Americano Contra o Aborto Inseguro), Peru, Costa Rica, Colombia, Brasil, 2018.

LUTE COMO UMA MENINA. Direção: Beatriz Alonso e Flávio Colombini, Brasil, 2016.

SEMENTES: mulheres pretas no poder. Direção: Éthel Oliveira, Julia Mariano, Brasil, 2020. 
'Em 2 de junho de 2020, o menino Miguel Otávio Santana da Silva, caiu do $9^{\circ}$ andar de um prédio em um condomínio de luxo, no Recife (PE). A mãe dele, Mirtes Renata Santana de Souza, havia deixado a criança sob os cuidados da patroa, Sarí Côrte Real, enquanto passeava com o cachorro da família dos chefes. Sarí se comprometeu a ficar com a criança por 10 ou 15 minutos. Nesse tempo, Miguel quis buscar a mãe e a patroa permitiu que ele entrasse no elevador sozinho, no $5^{\circ}$ andar, ela apertou o botão do último piso, mesmo ciente de que a criança buscava o térreo, o menino, de cinco anos, apertou outros botões aleatoriamente e desceu no $9^{\circ}$ andar, de onde cairia acidentalmente minutos depois, de uma altura de 35 metros. Fonte: https://www.brasildefato.com.br/2021/06/02/um-ano-do-caso-miguel-patroa-que-deixou-crianca-cair-do-9andar-segue-sem-punicao Acesso em: 20.jan.22

ii Disponível no canal do Tempero Drag. https://www.youtube.com/watch?v=OEr0kbUrNUs Acesso em: 20.jan. 22

iii AMAZÔNIDAS é um poema da indígena ativista, poeta e escritora Márcia Kambeba. Disponível no Canal Curta. https://www.youtube.com/watch?v=y307DOD9pSM Acesso em: 20.jan.22

iv Em 2016, houve início uma onda imigratória de venezuelanos para o Brasil, causada por questões políticas e econômicas. Os estados de Roraima e Amazonas foram os mais procurados pelas/os refugiadas/os, pela proximidade geográfica das fronteiras. O fluxo se intensificou no Amazonas, em 2017, com a ocupação da Rodoviária da cidade de Manaus. De acordo com os dados do Alto Comissariado das Nações Unidas para Refugiados (ACNUR), entraram no Brasil, no período entre 2017 e 2019, 240 mil venezuelanos. 94.400 solicitaram refúgio e 65.600 estão em processo de regularização, com autorização provisória. Disponível em: https://tede.ufam.edu.br/bitstream/tede/8133/4/Disserta\%c3\%a7\%c3\%a3o_KellyRocha_PPGSS.pdf Acesso em: 02 mar. 2021.

v Quanto ao aumento do volume de trabalho das mulheres durante a pandemia, corroboro com a pesquisa de Lemos, Barbosa e Monzato (2020), que analisam a situação: "Dados divulgados pelo IBGE (2019) sobre "outras formas de trabalho" apontam que a taxa de realização de afazeres domésticos das mulheres foi de $92,2 \%$ ratificando sua superioridade em relação ao percentual de homens, que totalizou 78,2\% (IBGE, 2019). Tais indicadores nos levaram a pressupor que a súbita necessidade de ter que trabalhar em casa, cuidar dos afazeres domésticos e dos filhos trouxe mais sobrecarga para as mulheres" (p. 389). Disponível em: https://www.scielo.br/pdf/rae/v60n6/0034-7590-rae-60-06-0388.pdf Acesso em: 02 mar. 2021. O Instituto de Pesquisa Econômica Aplicada (IPEA) publicou, em junho de 2020, uma Nota Técnica intitulada: Vulnerabilidades das Trabalhadoras Domésticas no Contexto da Pandemia de Covid-19 no Brasil, realizado pelas pesquisadoras: Luana Pinheiro, Carolina Tokarski e Marcia Vasconcelos, com informações importantes sobre as trabalhadoras domésticas no Brasil. Disponível em:

http://repositorio.ipea.gov.br/bitstream/11058/10077/1/NT 75 Disoc Vulnerabilidades\%20das\%20Trabalhador as\%20Domesticas.pdf Acesso em: 14 jan.2020.

${ }^{\mathrm{vi}}$ Dados publicados no $14^{\circ}$ Anuário Brasileiro de Segurança Pública, divulgado pelo Fórum Brasileiro de Segurança Pública. Disponível em: https://forumseguranca.org.br/wp-content/uploads/2020/10/anuario-14-2020v1-interativo.pdf Acesso em:15 fev. 2021.

vii Oswald de Andrade. Manifesto Antropofágico. Disponível em: https://www.ufrgs.br/cdrom/oandrade/oandrade.pdf Acesso em: 30 mar. 2021.

viii Prática tradicional na Amazônia, que indica trabalho coletivo. A comunidade se reúne para ajudar os vizinhos que precisam realizar colheita, construção de casa ou outro serviço. "A prática do ajuri é costumeira nas comunidades de populações tradicionais, consistem em uma técnica/método de trabalho coletivo, que visa auxílio mútuo entre as famílias no roçado, plantio, colheita e outras atividades em que se faz necessária a participação de várias pessoas, constituindo um espaço de solidariedade, sociabilidade e responsabilidade, entre os comunitários, provendo sua vivência com meio ambiente rural e interação social econômica, política e espiritual”. MERIGUETE, Indramara Lôbo de Araújo Vieira; ARAÚJO, Maria Isabel de; SOUSA, Silas Garcia Aquino de. Ajuri nas Florestas: uma prática real. Disponível em: https://ainfo.cnptia.embrapa.br/digital/bitstream/item/156370/1/Ajuri.pdf Acesso em: 28 fev.2021.

${ }^{i x} \mathrm{Na}$ literatura sobre colonialidade do poder, não há consenso entre o uso dos termos decoloniais ou descoloniais. A opção de uso do decolonial aqui, segue as ideias de Quijano (2002; 2005) e Mignolo (2003; 2017).

x Poema Educação Indígena, de Márcia Wayna Kambeba. Fonte: https://educapes.capes.gov.br/bitstream/capes/553433/5/Poema\%20Educa\%C3\%A7\%C3\%A3o\%20Ind\%C3\%A Dgena.pdf Acesso em: 20.jan. 